\title{
Individual differences in visual-geometric illusions: Predictions from measures of spatial cognitive abilities
}

\author{
STANLEY COREN \\ University of British Columbia, Vancouver, British Columbia, Canada \\ and \\ CLARE PORAC \\ University of Victoria, Victoria, British Columbia, Canada
}

\begin{abstract}
A sample of 490 observers was tested on 26 illusion variants and five tests of spatial ability. There was some suggestion that overall perceptual accuracy was related to perceptual ability. More importantly, the individual differences in the magnitude of visual illusions scores were significantly predicted by spatial abilities measures. The general relationship suggested that higher levels of spatial ability were associated with reduced illusion magnitude; however, a canonical correlation analysis revealed that the direction of this relationship depended on the type of illusion. Illusions of linear extent showed an inverse relationship between the two sets of measures, with higher levels of spatial abilities associated with lower degrees of illusion susceptibility. High spatial skills scores were related positively to illusion magnitude for illusions of area and direction.
\end{abstract}

As any perceptual researcher who has studied visual illusions can attest, one of the most striking qualities of the data derived from such stimuli is the degree of variability across individuals. Given any specific visualgeometric illusion, observers range from high to low levels of measured illusion susceptibility. This variability is not due to measurement error, since observers are consistent within their settings and reliably reproduce approximately the same degree of illusion magnitude on repeated measures.

The sources of these wide individual differences have not been established. However, there have been occasional suggestions that these observer differences are due, in part, to differences in cognitive capacity, intelligence, viewing strategy, or cognitive style. Historically, this approach has been responsible for the study of age trends in visual illusions. Binet (1895) used age as an observer variable when studying illusions, not because of an interest in age changes per se, but because studying individuals of different ages provided a simple means of obtaining samples of different levels of cognitive ability. He attributed the observed reduction of the Müller-Lyer illusion with increasing chronological age to the fact that individuals with greater cognitive skills (adults vs. children) are less susceptible to visual-geometric illusions.

This research was supported in part by grants from the Natural Sciences and Engineering Research Council of Canada, and it represents the equal and shared contribution of both authors. Reprint requests should be sent to Stanley Coren, Department of Psychology, 2075 Wesbrook Mall, University of British Columbia, Vancouver, British Columbia V6T IW5, Canada.
The presumed inverse relationship between cognitive ability and visual illusion susceptibility suggested by $\mathrm{Bi}-$ net (1895) has persisted, at least at the informal level. Seashore (1961) provided in his autobiography an amusing statement concerning this viewpoint. His graduate research, conducted around the turn of the century, included some work on the Müller-Lyer illusion. He noted that:

Up to that time the theory had prevailed that a person who was subject to such gross illusions was abnormal or at least a weakling.... I produced a rather telling shock and reaction to this by turning the guns on professors and brilliant graduate students, showing that the normal illusion obtained for them quite in the same manner and degree. (Seashore, 1961, p. 249)

Occasional references to the relationship between intelligence and/or cognitive style and illusion magnitude continue to appear in the literature (see Coren \& Girgus, 1978 a, for a review, or Piaget, 1969, for a more philosophical discussion). It is not surprising that the aspect of intelligence that has been most discussed in this regard is spatial cognitive ability. This aspect of spatial intelligence usually is measured psychometrically by tests that assess an observer's skill with manipulation of nonverbal sets of stimuli. Choosing correct versus incorrect object rotations or pattern foldings, assembling or matching patterns, or perceptually disembedding simple visual forms from more complex ones are examples of spatial abilities tasks (L. J. Harris, 1981; McGee, 1979). At the theoretical level, such tests are believed to assess an individual's ability to attend to, process, and manipulate spa- 
tial inputs and concepts, but they are also thought to demonstrate the application of an internal metric system to the representation of physical space (see Just \& Carpenter, 1985; McGee, 1979). To the extent that such a view is correct, it becomes apparent why we might expect these spatial abilities to interact with illusion susceptibility. In many respects, visual-geometric illusions may be interpreted as systematic distortions of the internal representation of the metric of a visual stimulus, either in terms of either direction or size. These "misconstructions" of the spatial reality are clearly due, at least in part, to the manner in which either the spatial aspects of the stimulus itself or its relationship to the auxiliary lines that induce the distortion are processed cognitively (Coren \& Girgus, 1978a, 1978b; Coren \& Porac, 1983). Since visual illusions and spatial abilities seem, therefore, to share some theoretical components, and since both are subject to wide individual variations, it seems reasonable to ask whether there is some relationship between these two behavioral expressions of spatial processing.

Although there have not been many attempts to study the interrelationship between spatial skill and visual illusions, one systematic series of studies has been mounted by Witkin and his colleagues (Witkin, 1967). Using one class of spatial ability (viz., the ability to isolate a simple figure embedded in a complex array), they were able to predict susceptibility of individuals in the rod and frame illusion, where the apparent orientation of a line is influenced by the orientation of the surrounding contextual frame. This illusion is similar to many other orientation illusions in a number of respects (see Coren \& Hoy, 1986). Several studies indicate that individuals who are poor at the spatial disembedding task (designated as field dependent) show large illusion magnitudes as contrasted with individuals who are better at the spatial task (field independent) and less susceptible to the illusion (see Coren \& Girgus, 1978a, for a review; also, McClellan, Bernstein, \& Garbin, 1984; Witkin, Dyk, Faterson, Goodenough, \& Karp, 1962).

Unfortunately, the Witkin approach dealt with only one class of spatial cognitive measure and one class of illusion figure. However, there are a large number of visualgeometric illusions (see Coren \& Girgus, 1978a) and a variety of spatial cognitive abilities that might be considered (cf. McGee, 1979). Coren, Girgus, Ehrlichman, and Hakstian (1976) attempted to behaviorally classify illusion configurations. They argued that individual differences in the perception of illusions may be due to differential sensitivity of observers to different illlusion-inducing mechanisms. Suppose, for instance, that an individual is highly sensitive to illusion mechanism $A$ and only weakly sensitive to illusion mechanism B. Such a person might be expected to show large illusion magnitudes in all configurations that are dominated by mechanism $A$ and only weak illusion strength for figures that are predominantly due to mechanism B. On the other hand, a person weakly responsive to mechanism $A$ and strongly responsive to mechanism B would show exactly the opposite pattern.
Notice that this implies that one could use the individual difference patterns in responsiveness to illusions to group illusions into those that are mainly due to mechanism $A$ and those that are mainly due to mechanism B. Based on this reasoning, Coren et al. developed an empirical taxonomy, using a set of 45 illusion configurations and 221 observers. The results were factor analyzed, and two global taxonomic groupings of illusions emerged. The first group, illusions of linear extent, includes figures such as the Müller-Lyer and the horizontal-vertical illusion. The second group, illusions of direction and area, includes figures such as the Zoeliner and the Delboeuf illusions. Since these two groupings emerged from the empirical covariation of the illusion magnitudes across configurations, it seems likely that each of the illusions within a grouping share some common mechanisms. However, there is no reason to expect that spatial skills interact in the same manner for illusions that fall into different classes. It is more likely that the different categories of illusions might be differentially affected by particular dimensions of spatial abilities.

To assess whether spatial skills play a role in the determination of the magnitude of visual-geometric illusions, and also to provide an evaluation of whether these individual difference factors affect the two major classes of illusions differentially, a fairly large-scale study is required. First, a reasonably large sample of visual illusions is required, with prototypical configurations drawn from both of the major illusion groups. Second, a fairly large range of spatial skills should be tested, since there are few a priori indications as to which spatial skills might be most relevant. Finally, a fairly large sample of subjects is required, since one would expect most of the effects to be modest in magnitude, and one would like to utilize some of the more powerful multidimensional statistical analysis techniques to explore the pattern of results. The study described below was designed with these requirements in mind.

\section{METHOD}

\section{Subjects}

Our observers were 495 students enrolled in an introductory psychology course at the University of Victoria. Although the use of college students as observers somewhat restricts the range of spatial abilities, our prior studies have shown that a first-year student population produces enough variability in cognitive testing to provide a wide range of scores (see Porac \& Coren, 1981a). The final sample included 223 males and 272 females.

\section{Stimuli and Procedure}

Visual illusion stimuli and testing procedure. Our illusion stimuli were 26 figural variants of common visual-geometric illusions. These included illusions of extent, direction, and size contrast. We chose prototypical illusion configurations, representing both of the major groupings of illusions (distortions of linear extent and distortions of direction and area), as defined empirically in the factor analytic illusion taxonomy of Coren et al. (1976). The specific length illusions included four Müller-Lyer variants: the standard form (Figure 1A); an "exploded" version, where the wings 

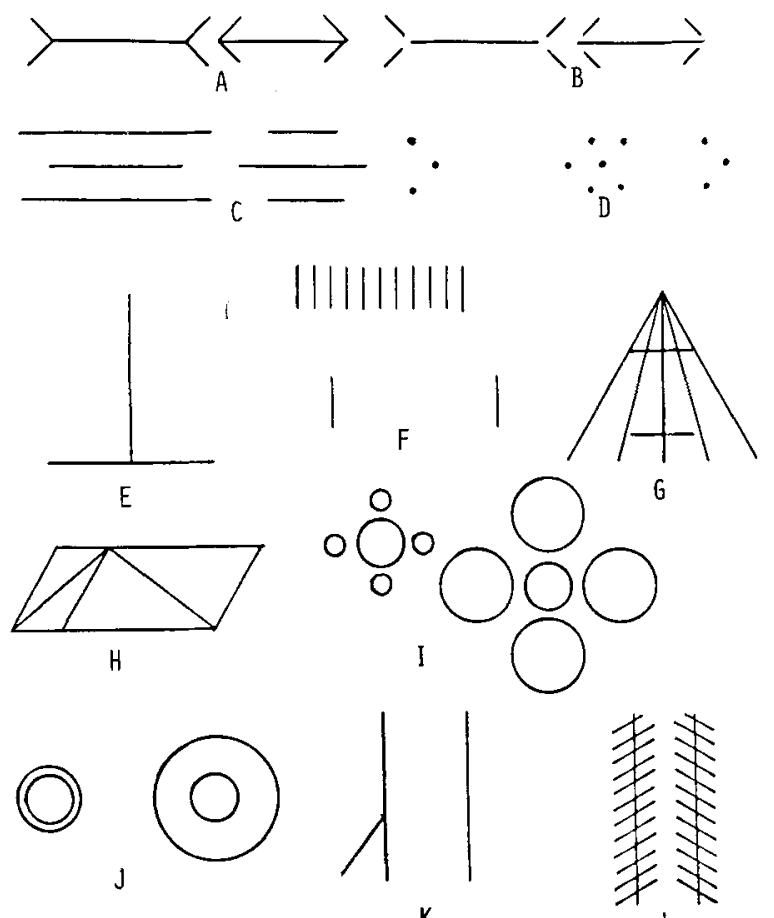

G

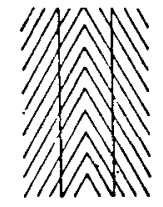

$M$

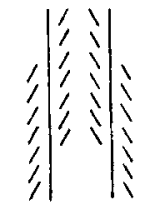

N
Figure 1. Illusion figures used in this study: (A) standard MüllerLyer, (B) exploded Müller-Lyer, (C) Piaget Müller-Lyer, (D) dot Müller-Lyer, (E) horizontal-vertical, (F) Oppel-Kundt, (G) Ponzo, (H) Sander parallelogram, (I) Ebbinghaus, (J) Delboeuf, (K) Poggendorff, (L) standard Zoellner 30, (M) herringbone Zoellner, (N) exploded Zoellner.

are separated from the shafts by a gap (1B); Piaget's parallel line form (1C); and Coren's dot form (1D). The other illusions of linear extent included the inverted-T form of the horizontal-vertical illusion (1E), the Oppel-Kundt illusion (sometimes referred to as the divided space/undivided space illusion) (IF), the Ehrenfel's variant of the Ponzo illusion (1G), and Sander's parallelogram (1H). We used the following illusions of area and direction: the Ebbinghaus (often referred to as Titchner's circles) (1I), the Delboeuf illusion $(1 \mathrm{~J})$, the Poggendorff $(1 \mathrm{~K})$ with transversals at $30^{\circ}$, $45^{\circ}$, and $90^{\circ}$ from the vertical, and three variants of the Zoellner illusion. The Zoellner variants were a standard two-line figure with $30^{\circ}$ transversals (1L), a herringbone pattern with $60^{\circ}$ transversals (1M), and an "exploded" or separated pattern with $60^{\circ}$ transversals (1N). Those illusions in which there are both over- and underestimation components were tested separately for each illusion configuration.

Ilusion figures were presented in booklet format to permit group testing. Subjects indicated the apparent size of the designated portions of the illusions of linear extent by selecting from a graded series of comparison stimuli the line that appeared to be equal to the test extent. The graded comparison series consisted of 21 horizontal lines, varying in length from 62 to $106 \mathrm{~mm}$ in $1-\mathrm{mm}$ steps. The comparison stimuli were presented immediately adjacent to the illusion arrays so that both the illusion configuration and the comparison stimuli were simultaneously in view. Each comparison line had a number, and observers chose the number of the horizontal line that appeared to be equal to the designated length in the illusion pattern. Coren and Girgus (1972a) demonstrated that this procedure produces results that are comparable to measurements utilizing continuously adjustable line lengths as the dependent variable. Prior to being tested on the illusion configurations, each subject was presented with four undistorted practice lines, which served to familiarize observers with the procedure and to check on their understanding and reliability.

Illusions of circular area were measured in a similar manner. We presented a graded series of circular stimuli, ranging from $10 \mathrm{~mm}$ to $30 \mathrm{~mm}$ in diameter in 1-mm steps. Instructions and presentation were similar to those used for illusions of linear extent. Four undistorted practice circles were presented to observers both to familiarize them with the procedure and to serve as a performance check. Coren and Girgus (1972a) also validated this method of illusion measurement and showed that it is as valid and reliable as the method of adjustment for illusions involving distortions of circle size. These applications of the method of selection from a graded series have been used in a number of studies and have proven to be reliable enough to measure systematic age trends in illusions of both linear extent (Coren \& Porac, 1978) and circular area (Porac \& Coren, 1981b).

We assessed the magnitude of the Poggendorff and Zoellner illusions using the procedure validated by Coren and Porac (1979) for group testing. The Poggendorff variants tested employed four different angles of intersection between the transversal and the vertical line . A practice stimulus had a $90^{\circ}$ transversal, and the test stimuli had $30^{\circ}, 45^{\circ}$, and $60^{\circ}$ transversal angles. Instead of the right-hand vertical line, shown in Figure 1K, we placed a column of letters $5 \mathrm{~cm}$ to the right of the left-hand vertical line. Observers visually estimated the point at which each of the four transversals, if extended, would intersect the vertical column and designated it by indicating the letter found at that locus. We measured the Zoellner illusion in a similar manner. We placed a row of letters $5 \mathrm{~cm}$ above each figure. Observers indicated the letters that the vertical lines would cross if extended (in imagination) toward the top of the page. Coren and Porac (1979) verified the ability of this measurement procedure to produce classically obtained variations in illusion magnitude with changes in the stimulus configurations.

Spatial abilities tests and testing procedures. Spatial cognitive abilities include a broad range of nonverbal visualization and orientation skills (see McGee, 1979). Based upon the existing data as to the cognitive processes most likely to be involved in illusion formation (e.g., Coren \& Girgus, 1978a), we reasoned that abilities associated with the visualization of stimulus objects in space, those involved in disembedding simple stimulus components that have been integrated into complex contexts, and those associated with the integration or assimilation of stimuli into larger patterns would be among those spatial skills most likely to be related to visual illusion susceptibility. Our study employed five different measures of spatial ability, including spatial visualization, disembedding, closure, and search.

Spatial visualization was tested via mental rotation using a variant of a test devised by French (1963). Observers discriminated between two-dimensional (rotations on the $x$ and $y$ axes, which are equivalent to sliding the object around on the page) and threedimensional (rotations on the $x, y$, and $z$ axes, which require the object to be lifted off the page and flipped over) transformations of a target visual form. A sample of this text appears in Figure 2A.

The ability to separate a simple figure from a more complex array was tested using an embedded figures test. We employed a variant of the Gottschaldt Figures Test (called embedded figures), popularized and adapted by Thurstone (1951). Observers decided which 


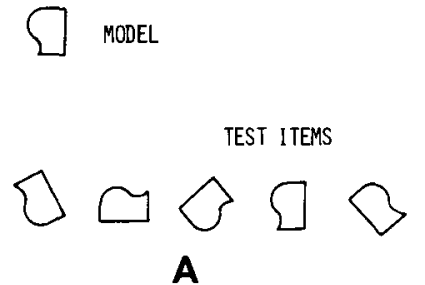

A

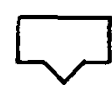

MODELS
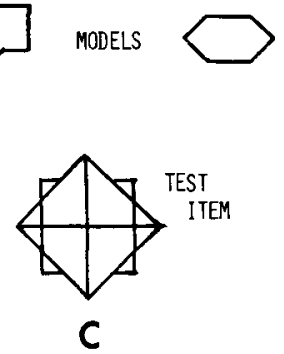

Figure 2. Samples of measures of spatial cognitive abilities used in this study: (A) mental rotation, (B) closure, (C) embedded figures, (D) figure match.

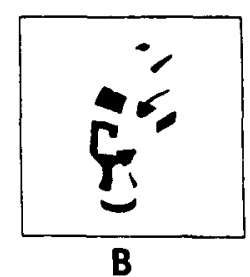

久 MODEL

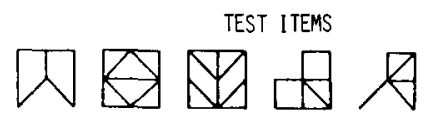

D of two figures was embedded in a complex pattern; they traced over
the outline of the figure to identify its location (see Figure $2 \mathrm{C}$ for an example.).

The next test involved a figure matching task. A simple target configuration was embedded in some, but not all, items in a series of complex distracter items. The individual items were fairly easy, and the task was to correctly identify as many patterns as possible that contained the target configuration. We modeled this task after one devised by French (1963), and an example is shown in Figure 2D.

We also employed a speeded search task, in which the observer quickly scanned columns of words to find the target letter $a$ contained in some, but not all, of the words. The embedded figures and figure matching tasks required separation of a simple component from a more complex context, whereas this task required a search for a stimulus element that was relatively freestanding and shared no contours with the surrounding "noise context" provided by other letters in the word.

Our final measure was designed to test the subject's ability to assimilate or integrate elements of an array. This involved a test of Gestalt completion (closure), based on the tests devised by Street (1931) and French (1963). The completion test contained stimuli composed of black spots representing parts of the contour of an object. The observer completed the object mentally and identified it (Figure 2B is an example).

The spatial abilities testing was conducted immediately after the measurements of illusion magnitude. Each of the five measures was timed, and each test score was the number of correct responses given during the allowed time period.

\section{RESULTS AND DISCUSSION}

\section{Spatial Cognitive Abilities and \\ Perceptual Accuracy}

We first examined the relationship among the measures of spatial abilities. The intertest correlations are shown in Table 1. As one can see, they present the typical pattern found in most abilities batteries, with low positive intercorrelations, all of which are statistically significant. The fact that there are significant correlations among the tests suggests that there is a common component in all of the measures, perhaps representing a general dimension of spatial ability that accounts for a small proportion of the variance (e.g., McGee, 1979). The fact that the correlations are not very high (accounting for less than $10 \%$ of the variance on average), however, also suggests that each test is tapping some unique aspect(s) of spatial ability not held in common with the other measures.

Sex-related variations in spatial abilities often have been reported (see L. J. Harris, 1981); therefore, we also explored the possibility of sex-related variance in our data. We found a small sex difference in the mean scores of the search and mental rotation tasks: Females performed better on search tasks, and males performed better on mental rotation tasks. Sex differences in mean scores did not occur in the other abilities measures. We chose to use the total sample in further analyses because of the lack of clear and consistent sex differences in our spatial abilities measures and the lack of sex differences in the correlations among the spatial abilities measures and the visualgeometric illusion scores. However, as an additional check, we performed duplicates of the analyses reported here using partial correlations with the effect of sex re-

Table 1

Correlations Among Measures of Spatial Cognitive Abilities

\begin{tabular}{|c|c|c|c|c|c|}
\hline & & Embedded & & Mental & Figure \\
\hline & Closure & Figures & Search & Rotation & Match \\
\hline Embedded Figures & $0.178 \dagger$ & & & & \\
\hline Search & $0.083^{*}$ & $0.100^{*}$ & & & \\
\hline Mental Rotation & $0.156 \dagger$ & $0.218 \dagger$ & $0.137 \dagger$ & & \\
\hline Figure Match & $0.105 \dagger$ & $0.380 \dagger$ & $0.093^{*}$ & $0.245 \dagger$ & \\
\hline
\end{tabular}

${ }^{*} p<.05 . \quad \dagger p<.01$. 
moved. These sex-partialed analyses produced patterns of results identical in pattern and significance to those of the whole sample discussed here.

Before considering our main question, let us first consider the relationship between spatial abilities and the accuracy of perceptual judgments in nonillusory situations. McClellan et al. (1984) found that scores on an embedded figures test predicted an observer's responsiveness to length cues within a figure. Following their finding, we explored the correlation between the observers' spatial skills measures and their responses to the eight control figures included in our study (four single circles of different diameters and four single lines of different lengths). We computed a composite score to quantify each observer's overall accuracy in assessing the diameters and lengths of these control stimuli by summing the absolute difference between the observer's judgment and the veridical length or diameter of each figure and then dividing by the number of judgments to obtain a mean. This measure assessed the average judgmental error, disregarding its direction (over- or underestimation). We computed bivariate correlations between the mean deviation score and observers' scores on the five spatial abilities measures. These correlations were negative for all five of the spatial measures. This result is one predicted by a hypothesis that higher levels of spatial ability (high scores) are associated with greater accuracy in perceptual judgments (low mean deviation). Three of the five correlations, namely those between the mean deviation and mental rotation $(r=-.11)$, search $(r=-.08)$, and figure match $(r=-.09)$, were statistically significant $(p<.05, d f=$ 495). Thus individuals with higher spatial abilities scores were more accurate in judgments of stimulus size. However, the size of the correlations suggests that the practical impact of this relationship is not great.

\section{Spatial Cognitive Abilities and Illusion Susceptibility}

Let us now consider the relationship between levels of spatial ability and visual-geometric illusion magnitude by computing bivariate correlations between illusion scores and spatial abilities scores. Individuals showed constant errors of over- and underestimation, even when judging nonillusion figures (and, as reported above, we found that magnitude of these errors were weakly related to spatial abilities scores). Therefore, we conducted our analyses using partial correlations that removed the effect of any biases inherent in the judgment of the eight control figures. We further simplified the interpretation of the correlation coefficients by scoring illusion magnitudes (differences between the veridical extents and the observer's judgments) as positive when they were in the usually expected direction, regardless of whether the illusion typically causes over- or underestimation errors. In this scoring procedure, a positive correlation between the response to an illusion figure and a particular test of spatial ability implies that higher spatial abilities scores predict higher illusion magnitude and a negative correlation implies the converse.
The correlation matrix that resulted from this analysis is shown in Table 2. Even a cursory look at this table suggests that individual differences in spatial cognitive ability do predict illusion strength. Seventy-two $(55 \%)$ of the 130 correlations were statistically significant, with $p<.05$ or better. The likelihood that so many significant correlations would be obtained by chance alone is extremely low $(z=26.35, p<.0001)$. Of the 72 significant correlations, 56 (78\%) were negative. This preponderance of negative correlations was a significant departure from expected proportions $(z=4.71$, $p<.001)$. Negative correlations indicate that higher spatial ability was associated with lower illusion magnitude. Thus we may conclude that measured illusion strength was related inversely to spatial abilities for the majority of illusion configurations.

\section{Spatial Abilities and Classes of Visual Illusions}

As we described earlier, Coren et al. (1976) developed an empirical taxonomy of visual-geometric illusions based on the covariation of illusion magnitudes for different configurations. They found two, relatively independent, classes of visual illusions. One class includes illusions of linear extent, of which the Müller-Lyer under- and overestimations are a clear prototype. The second class incorporates illusions of direction and area; the Zoellner direction distortion and the Delboeuf size illusion exemplify this class. We grouped the correlations in Table 2 according to these two classes, and scrutiny of the divided matrix showed differences in the proportion of positive and negative correlations within the two categories. All of the 33 statistically significant correlations were negative in the direction and area illusion group. The pattern in the linear extent category was different; only $59 \%$ of the correlations were negative. This difference in proportions between the two groups was statistically significant $\left[x^{2}(1)=45.49, p<.001\right]$. This result suggests that the direction of the association between levels of spatial ability and illusion strength is specific to a class of illusions. The general conclusion that we reached above, that higher levels of spatial ability correlate with lower illusion susceptibility, seems, on the basis of this reconsideration of the patterns of correlation, to hold for one class of illusions (direction and area) but not for the other (linear extent).

To gain a clearer understanding of this apparent classspecific relationship between visual illusion magnitude and spatial abilities, we decided to use a canonical correlation analysis. Since this is a statistical procedure that may not be very familiar to many experimental psychologists, it may be helpful for us to indicate some features of this statistic that are particularly useful in the present context of the problem under investigation here.

Canonical correlation is a member of a closely interrelated group of multivariate linear techniques that includes factor analysis and discriminant analysis $(R$. J. Harris, 1975; Marascuilo \& Levin, 1983). A canonical correlation analysis is similar to a regression analysis, ex- 
Table 2

Correlation Between Illusion Magnitude and Spatial Skills

\begin{tabular}{|c|c|c|c|c|c|}
\hline & \multicolumn{5}{|c|}{ Spatial Skills Tests } \\
\hline & Closure & $\begin{array}{c}\text { Embedded } \\
\text { Figures }\end{array}$ & Search & $\begin{array}{c}\text { Mental } \\
\text { Rotation }\end{array}$ & $\begin{array}{l}\text { Figure } \\
\text { Match } \\
\end{array}$ \\
\hline \multicolumn{6}{|c|}{ Illusions of Linear Extent } \\
\hline Müller-Lyer + & $.079 *$ & $-.150 \dagger$ & $-.208 \dagger$ & .019 & -.039 \\
\hline Müller-Lyer - & .016 & $.269 \dagger$ & $-.127 \dagger$ & $.226 \dagger$ & $.131^{*}$ \\
\hline Exploded Müller-Lyer + & -.030 & $-.109 \dagger$ & $-.157 \dagger$ & .043 & $-.079 *$ \\
\hline Exploded Müller-Lyer - & .051 & $.233 \dagger$ & -.009 & $.081 *$ & $.190 \dagger$ \\
\hline Piaget Müller-Lyer + & .001 & .008 & $-.147 \dagger$ & .070 & .058 \\
\hline Piaget Müller-Lyer - & .066 & $.263 \dagger$ & $-.120 \dagger$ & $.216 \dagger$ & .060 \\
\hline Dot Müller-Lyer + & $.092 *$ & .012 & $.078^{*}$ & .037 & $.097 *$ \\
\hline Dot Müller-Lyer - & .037 & $.094^{*}$ & $-.100 *$ & -.010 & .057 \\
\hline Oppel-Kundt + & $.101^{*}$ & .056 & -.070 & .025 & .015 \\
\hline Oppel-Kundt - & .032 & .038 & -.064 & $.090 *$ & $-.079 *$ \\
\hline Sander Parallelogram + & .041 & $-.179 \dagger$ & $-.135 \dagger$ & $-.109 \dagger$ & -.064 \\
\hline Sander Parallelogram - & -.021 & -.032 & $-.133 \dagger$ & $-.101 *$ & .010 \\
\hline Ponzo + & .023 & .009 & $-.092 *$ & .036 & .048 \\
\hline Ponzo - & $.101 *$ & $-.086 *$ & -.070 & .025 & .015 \\
\hline Horizontal-Vertical + & .042 & $-.100^{*}$ & -.013 & $-.084 *$ & -.048 \\
\hline Horizontal-Vertical - & .056 & $-.104 *$ & $-.136 \dagger$ & $-.096^{*}$ & -.042 \\
\hline \multicolumn{6}{|c|}{ Illusions of Direction and Area } \\
\hline Ebbinghaus + & -.023 & $-.181 \dagger$ & $-.113 \dagger$ & $-.187 \dagger$ & $-.261 \dagger$ \\
\hline Ebbinghaus - & .026 & $-.084^{*}$ & $-.137 \dagger$ & $-.203 \dagger$ & $-.138 \dagger$ \\
\hline Delboeuf + & -.073 & -.043 & $-.165 \dagger$ & -.065 & $-.120 \dagger$ \\
\hline Delboeuf - & $-.093^{*}$ & -.037 & $-.124 \dagger$ & $-.163 \dagger$ & -.034 \\
\hline Poggendorff $\mathbf{3 0}$ & .001 & $-.094^{*}$ & -.003 & $-.136 \dagger$ & $-.094^{*}$ \\
\hline Poggendorff 45 & $-.095^{*}$ & $-.161 \dagger$ & -.016 & $-.184 \dagger$ & $-.137 \dagger$ \\
\hline Poggendorff 60 & $-.145 \dagger$ & $-.171 \dagger$ & -.061 & $-.100 *$ & $-.134 \dagger$ \\
\hline Standard Zoellner 30 & -.020 & $-.104 \dagger$ & $-.137 \dagger$ & -.062 & -.069 \\
\hline Herringbone Zoellner & $-.083^{*}$ & $-.128 \dagger$ & -.032 & $-.119 \dagger$ & -.060 \\
\hline Exploded Zoellner & $-.090^{*}$ & $-.114 \dagger$ & .055 & $-.087^{*}$ & $-.076 \dagger$ \\
\hline
\end{tabular}

Note $-+=$ Over-estimation segment of illusion. $-=$ Under-estimation segment of illusion. ${ }^{*} p<.05 . \quad \dagger p<.01$.

cept that there are multiple dependent and multiple independent variables. The analysis begins with two sets of variables that have a theoretical meaning. For our purposes, the first set included the scores on the five measures of spatial abilities, which were, nominally, the independent variables. The second set, or dependent variables, included the measures of illusion magnitude, divided into illusions of direction and area and illusions of linear extent. For each subject, we computed a composite score from the set of 16 illusions of linear extent and another composite score from the 10 illusions of direction and area. The two composites were obtained simply by summing all of the illusion magnitudes in each of the illusion groupings.

Once the variables are defined, canonical correlation techniques determine the linear combination of spatial skills measures that are most highly correlated with linear combinations of the illusion magnitude scores. This technique has been characterized as a "double-barrelled principal components analysis" (Tatsuoka, 1971). One attempts to derive a linear combination of the spatial abilities measures that maximizes the correlation between it and a linear combination of illusion scores. Several linear combinations of the two sets of variables can usually be derived, and the strength of each relationship is shown by the magnitude of the canonical correlation coefficients.
The derivation of each pair of linear combinations also results in a set of weighting coefficients known as canonical variates. These are similar to beta weights in a multiple regression equation. Since these are the coefficients applied to the two sets of variables in standard score form, they do not depend on the original measurement scale. Therefore, one can interpret them as indicating the direct contribution of each standardized variable to the total variance of the composite score.

Table 3 shows the results of this analysis. We found two significant canonical correlations. The first $(r=0.29)$ represents the canonical variates that have the largest correlation between illusion magnitude and spatial cognitive abilities measures, and it was statistically significant $\left[\chi^{2}(10)=47.98, p<.001\right]$. This first correlation clearly predicts the illusions of direction and area, which have a weighting of 0.894 , as opposed to the illusions of linear extent, which have a weighting of 0.336 . The canonical variates are negative, confirming the trend of the simple correlation matrix of Table 2 . Individuals with higher spatial abilities scores showed lower illusion magnitude scores when tested on illusions of direction and area. The best predictors of illusion magnitude were the embedded figures, mental rotations, and closure tasks.

The first canonical correlation represents the linear combination of variables producing the maximum corre- 
Table 3

Canonical Correlation Between Measures of Spatial Cognitive Abilities and Composite Husion Magnitude Scores

\begin{tabular}{lcc}
\multicolumn{2}{c}{ Abilities and Composite Husion Magnitude Scores } \\
\cline { 2 - 3 } & \multicolumn{2}{c}{ Canonical Variables } \\
\cline { 2 - 3 } & (Direction) & $\begin{array}{c}\text { II } \\
\text { (Extent) }\end{array}$ \\
\hline Cognitive Skills \\
Closure & -.335 & .742 \\
Embedded Figures & -.595 & -.780 \\
Search & -.177 & .079 \\
Mental Rotations & -.338 & .301 \\
Figure Match & -.166 & .079 \\
& Illusion Composites & \\
Direction and Area & .894 & -.471 \\
Linear Extent & .336 & .953 \\
\hline
\end{tabular}

lation, and no constraints are placed on the nature of the combination. However, other meaningful sets of linear combinations of the variables are also possible. Each subsequent canonical correlation is smaller than the first and accounts for a smaller portion of the total variance. In addition, a second canonical correlation must be uncorrelated with the first, and any further ones must be uncorrelated with all predecessors. In other words, a second canonical correlate works with residuals to explain the variance left unexplained by the prior relationship.

Our second canonical correlation $(r=0.17)$ was also significant $\left[\chi^{2}(4)=11.41, p<.02\right]$, and it was, as expected, smaller than the first. This second set of variates predicted the illusions of extent, as indicated by the large weighting of 0.953 for linear extent. There was a much smaller loading for the illusions of direction and area; also, it was opposite in sign $(-0.471)$. The individual canonical loadings of the spatial abilities tests were positive, except for that of the embedded figures test. This result suggests that higher spatial abilities scores are associated with larger magnitudes of illusions of extent, a finding opposite to that observed for illusions of direction and area, where greater spatial ability predicted smaller illusion magnitudes.

\section{GENERAL DISCUSSION}

There were two general questions that we hoped to address in this study. The first dealt with a determination as to whether the individual differences in the magnitude of measured illusory distortions could be related to individual variations in spatial ability. The answer to this question seems rather unambiguously affirmative, since $55 \%$ of the simple correlations between illusion magnitude and the individual spatial skills tests were statistically significant. The size of these correlations is generally modest; however, that is to be expected, since spatial ability is not, in and of itself, a causal mechanism, as is lateral inhibition or misapplied constancy scaling. Rather, it serves to modulate the size of the observed distortion by interacting with the primary causal mechanisms (presumably those with a more cognitive, rather than structural, basis).

Although the individual correlation between any given test and any one illusion is not very large, the compound effect of spatial ability on the magnitude of illusion measured is substantial. It can be estimated directly from the canonical correlations obtained between the tests and the composite illusion magnitude for the two illusion classes. As in standard product-moment correlations, the amount of variance explained by the relationship is given by the square of the correlation coefficient. Thus we can estimate that $8.4 \%$ of the individual variability in illusions is accounted for by variation in spatial ability by the first canonical correlation, whereas $2.9 \%$ of the variance is explained by the second canonical correlate. Since the two correlations are orthogonally derived (with the second canonical correlation based upon the residuals after the first is extracted) the total percentage of variance explained is actually the sum of these two values, or $11.3 \%$, which is a sizable effect. Thus although illusions are not caused by spatial ability, $11.3 \%$ of the variability among observers in illusion magnitude is accounted for by differences in spatial ability.

The second question that stimulated this research was conditional in nature. We asked whether, given a relationship between spatial skills and illusion magnitude, these effects manifest themselves differently for the two global classes of illusion (illusions of linear extent vs. illusions of direction and area), as empirically defined in the Coren et al. (1976) classification study. Again, the data are relatively unambiguous. Although both classes of illusion do seem to be related to measures of spatial ability, the magnitude of illusions of direction varies inversely with spatial skill measures, whereas the magnitude of illusions of linear extent is directly proportional to spatial ability (when one considers only the residuals). Coren et al. (1976) offered their taxonomic classification for descriptive purposes but speculated that the empirical derivation of the classification scheme implied differences in underlying causal structure between illusions of extent and illusions of direction and area. The fact that spatial abilities interact differently with these two categories of illusion seems to support this contention that there may be different underlying causal mechanisms for the two classes of distortion.

Given the major finding that spatial abilities seem to be related to illusion magnitude, it is tempting to speculate on the specific mechanisms that are interacting with specific spatial abilities. For instance, it seems plausible that the embedded figures test (the best overall predictor of illusion strength) reflects an observer's ability to separate the test from accessory components in a figure, hence this test interacts with illusions explainable by the so-called confusion theories (see Coren \& Girgus, 1972b; Erlebacher \& Sekuler, 1969). It seems conceivable that the closure test is most predictive of illusions explainable by assimilation theories, which state that an observer ex- 
tracts a global impression of an array and then biases his or her judgments of components of the configuration toward this perceived gestalt (e.g., Müller-Lyer, 1889; Pressey, 1967a, 1967b, 1974). Since the mental rotations may well reflect three-dimensional visualization, it seems that scores on this test are most predictive when applied to distortions based on responses to depth information from those covert cues in the illusion stimulus array that evoke misapplied constancy scaling (see Coren \& Girgus, 1977; Gillam, 1971; Girgus \& Coren, 1975; Gregory, 1968; Ward, Porac, Coren, \& Girgus, 1977). Nevertheless, such speculation is not apt to be particularly fruitful at this stage of inquiry, since any given visual illusion is apt to be the product of complex interactions among many levels of perceptual processing (see Coren \& Girgus, 1978a, 1978b; Coren \& Porac, 1983; Coren \& Ward, 1979; Girgus \& Coren, 1982), and any one spatial ability test may reflect several spatial skill dimensions (see McGee, 1979). Hence, such specific speculations as to the underlying mechanisms in any particular illusion, based upon its relationship to a single test of spatial skill, does not seem to be defensible at this time.

Several conclusions are possible from these data. To begin with, it is now clear that intersubject variability in measures of illusion magnitude is related to individual differences in spatial cognitive abilities. Although, globally considered, higher levels of spatial abilities predict reduced levels of illusion susceptibility, the form of the relationship is not simple. Different patterns of interaction between spatial ability and illusion magnitude emerge as a function of the class of illusions considered, suggesting that different mechanisms may predominate in the two major categories of illusion. Finally, these data suggest that individual differences in the susceptibility to various visual-geometric illusions may be indicative of individual differences in the cognitive processing of perceptual and spatial information in general. It may well be the case that if we can develop techniques to isolate and measure specific dimensions of spatial cognition within individuals, application of techniques similar to those used in this study may allow us to more clearly define the various cognitive mechanisms that contribute to specific illusory distortions.

\section{REFERENCES}

Binet, A. (1895). La mesure des illusions visuelles chez les adultes et chez les enfants. Revue Philosophique, 40, 11-25.

Coren, S., \& Graus, J. S. (1972a). A comparison of five methods of illusion measurement. Behavior Research Methods \& Instrumentation, 4, 240-244.

Coren, S., Girgus, J. S. (1972b). Differentiation and decrement in the Mueller-Lyer illusion. Perception \& Psychophysics, 12, 466-470.

Coren, S., \& Girgus, J. S. (1977). Illusion constancies. In W. Epstein (Ed.), Stability and constancy in visual perception: Mechanisms and processes (pp. 255-283). New York: Wiley.

COREN, S., GIRGUS, J. S. (1978a). Seeing is deceiving: The psychology of visual illusions. Hillsdale, NJ: Erlbaum.
Coren, S., \& Girgus, J. S. (1978b). Visual illusions. In R. Held, H. Leibowitz, \& H. L. Teuber (Eds.), Handbook of sensory physiology: Volume VIII. Perception (pp. 549-568). Berlin: Springer-Verlag. Coren, S., Girgus, J. S., Ehruchman, H., \& Hakstian, A. H. (1976). An empirical taxonomy of visual illusions. Perception \& Psychophysics, 20, 129-137.

COREN, S., \& HoY, V. S. (1986). An orientation illusion analog to the rod and frame: Relational effects in the magnitude of distortion. Perception \& Psychophysics, 39, 159-163.

CoRen, S., \& Porac, C. (1978). A new analysis of life-span age trends in visual illusions. Developmental Psychology, 14, 193-194.

COREN, S., \& Porac, C. (1979). Techniques for the measurement of the Poggendorff and Zoellner illusions in large group situations. Bulletin of the Psychonomic Society, 13, 219-222.

Coren, S., \& Porac, C. (1983). The creation and reversal of the Mueller-Lyer illusion through attentional manipulation. Perception, 12, 49-54.

COREN, S., \& WARD, L. M. (1979). Levels of processing in visual illusions: The combination and interaction of distortion-producing mechanisms. Journal of Experimental Psychology: Human Perception \& Performance, 5, 324-335.

Erlebacher, A., \& Sekuler, R. (1969). Explanation of the MuellerLyer illusion: Confusion theory examined. Journal of Experimental Psychology, 80, 462-467.

FRENCH, J. W. (1963). Kit of reference tests for cognitive factors. Princeton, NJ: Educational Testing Service.

Gillam, B. (1971). A depth processing theory of the Poggendorff illusion. Perception \& Psychophysics, 10, 211-216.

Girgus, J. S., CoREN, S. (1975). Depth cues and constancy scaling in the horizontal-vertical illusion: The bisection error. Canadian Journal of Psychology, 29, 59-65.

Girgus, J. S., \& COREN, S. (1982). Assimilation and contrast illusions: Differences in plasticity. Perception \& Psychophysics, 32, 555-561.

GrEgoRY, R. L. (1968). Visual illusions. Scientific American, 219 , 66-76.

HARRIS, L. J. (1981). Sex related variations in spatial skill. In L. S. Liben, A. H. Patterson, \& N. Newcombe (Eds.), Spatial representation and behavior across the life span (pp. 83-128). New York: Academic Press.

HARRIS, R. J. (1975). A primer of multivariate statistics. New York: Academic Press.

Just, M. A., \& CARPenter, P. A. (1985). Cognitive coordinate systems: Accounts of mental rotation and individual differences in spatial ability. Psychological Review, 92, 137-172.

Marascuilo, L. A., \& LeVIN, J. R. (1983). Multivariate statistics in the social sciences: $A$ researcher's guide. Monterey, CA: Brooks/Cole.

McClellan, P. G., Bernstein, I. H., Garbin, C. P. (1984). What makes the Mueller a liar: A multiple-cue approach. Perception \& Psychophysics, 36, 234-245.

McGee, M. G. (1979). Human spatial abilities: Psychometric studies and environmental, genetic, hormonal, and neurological influences. Psychological Bulletin, 86, 889-918.

Müller-LyER, F. C. (1889). Optische Urteilstauschungen. DuboisReymonds Archive für Anatomie und Physiologie (Suppl. Vol., pp. 263-270).

PIAGET, J. (1969). The mechanisms of perception (G. N. Seagrine, Trans.). New York: Basic Books.

PORAC, C., \& COREN, S. (1981a). Lateral preferences and human behavior. New York: Springer-Verlag.

Porac, C., Coren, S. (1981b). Life-span age trends in the perception of the Mueller-Lyer: Additional evidence for the existence of two illusions. Canadian Journal of Psychology, 35, 58-62.

Pressey, A. W. (1967a). A theory of the Mueller-Lyer illusion. Perceptual \& Motor Skills, 25, 569-572.

Pressey, A. W. (1967b). A theory of the Mueller-Lyer illusion. Perceptual \& Motor Skills, 25, 641-644.

Pressey, A. W. (1974). Evidence for the role of attentive fields in the perception of illusions. Quarterly Journal of Experimental Psychology, 26, 464-471. 
SEASHORE, C. E. (1961). In C. Murchison (Ed.), A history of psychology in autobiography. New York: Russell \& Russell.

STREeT, R. F. (1931). A gestalt completion test. New York: Teacher's College, Columbia University.

TA TSUOKA, M. M. (1971). Multivariate analysis: Techniques for educational and psychological research. New York: Wiley.

Thurstone, L. L. (1951). An analysis of mechanical aptitude. In Psychometric Laboratory Report No. 62. University of Chicago.

Ward, L. M., Porac, C., Coren, S., Girgus, J. S. (1977). The case for misapplied constancy scaling: Depth associations illicited by illusion configurations. American Journal of Psychology, 90, 609-620.
WITkIN, H. A. (1967). A cognitive-style approach to cross-cultural research. International Journal of Psychology, 2, 233-250.

Witkin, H. A., Dyk, R. B., Faterson, H. F., GoOdenough, D. R., \& Karp, S. A. (1962). Psychological differentiation. New York: Wiley.

(Manuscript received August 20, 1986; revison accepted for publication December 9, 1986.) 